\title{
Prevalence of talipes equinovarus, congenital dislocation of the hip, cleft lip/cleft palate, Down syndrome and neural tube defects among live newborns in Anuradhapura, Sri Lanka.
}

\author{
A C D de Alwis ${ }^{1}$, K N S de Silva ${ }^{2}$, W D M S D Bandara ${ }^{3}$, T G P M Gamage ${ }^{2}$ \\ Sri Lanka Journal of Child Health, 2007; 36: 130-2
}

(Key words: prevalence, talipes equinovarus, congenital dislocation of hip, cleft lip/palate, Down syndrome, neural tube defects, Anuradhapura, Sri Lanka)

\begin{abstract}
Objective To determine the prevalence of talipes equinovarus, congenital dislocation of the hip, cleft lip/cleft palate, Down syndrome and neural tube defects among live newborns at Anuradhapura General Hospital, Sri Lanka.
\end{abstract}

Method Babies born from February 2002 to January 2003 were examined for the above five congenital anomalies. Anomalies were recorded in a register and live birth prevalence rate (LBPR) for each anomaly was calculated.

Results 9105 newborns were examined for the 5 selected congenital anomalies. LBPR per 10,000 live births of the 5 anomalies were as follows: talipes equinovarus 31.8 , congenital dislocation of hip 26.3, cleft lip/cleft palate 21.9, Down syndrome 20.8 and neural tube defects 13.2.

\section{Introduction}

In a unique developing country like Sri Lanka, where a dramatic decline in infant mortality is observed over the last half century, as a result of control of infectious diseases, congenital anomalies are emerging as a significant cause of ill health in childhood. Not only geographical and ethnic, even seasonal variation of congenital anomalies has been described and more recently a downward secular trend in the prevalence of some anomalies has been observed $^{1,2}$.

${ }^{1}$ Consultant Paediatrician, General Hospital, Ratnapura, ${ }^{2}$ Registrar, Lady Ridgeway Hospital for Children, Colombo, ${ }^{3}$ Consultant Paediatrician, Teaching Hospital, Kandy.

(Received on 10 December 2006. Accepted after revision on 18 March 2007)

\section{Objective}

The objective of the present study was to determine the prevalence of congenital talipes equinovarus (CTEV), congenital dislocation of the hip (CDH), cleft lip/cleft palate, Down syndrome and neural tube defects (NTDs) among live newborns at Anuradhapura General Hospital of the north-central province of Sri Lanka.

\section{Subjects and Method}

The study population consisted of all live babies born at Anuradhapura General Hospital over a one year period from February 2002 to January 2003. As a part of standard care a head to toe clinical examination of all newborns was performed by a paediatric house officer within 24-36 hours of birth. House officers were trained to perform a newborn examination to detect congenital anomalies at their induction by a consultant paediatrician. Following the initial screening by the house officer the diagnosis of an anomaly was confirmed by a registrar and/or consultant paediatrician. Anomalies were recorded in a register maintained at the special care baby unit.

The number of babies with each of the 5 selected congenital anomalies was totalled and LBPR for each anomaly calculated. The LBPR is defined as the number of live born affected babies divided by the number of live births during that period expressed per 10,000 births

\section{Results}

Over the period of one year 9105 newborns were screened. Table 1 shows the number of affected newborns against each of the 5 selected congenital anomalies and the calculated LBPR per 10,000 live births. 
Table 1

Prevalence of 5 selected congenital anomalies in Anuradhapura, 2001-2002

\begin{tabular}{|l|c|c|}
\hline Congenital anomaly & Number of Cases & Prevalence per 10,000 live births \\
\hline Talipes equinovarus & 29 & 31.8 \\
\hline Congenital dislocation of hips & 24 & 26.3 \\
\hline Cleft lip/ cleft palate & 20 & 21.9 \\
\hline Down syndrome & 19 & 20.8 \\
\hline Neural tube defects & 12 & 13.2 \\
\hline Anencephaly & 06 & \\
\hline Meningomyelocele & 05 & \\
\hline Encephalocoele & 01 & \\
\hline
\end{tabular}

\section{Discussion}

The incidence of CTEV varies widely with respect to race and geography. In Japan, this condition affects approximately 5 per 10,000 live births, and in natives of the South Pacific, the incidence jumps to nearly 70 per 10,000 live births and in Caucasians the incidence is 12 per 10,000 live births $^{3}$. In our study, the prevalence of CTEV was 31.8 per 10,000 live births. The overall prevalence of true CDH in USA is 10 per 10,000 births; it is greater among Native Americans but rare in infants of African descent ${ }^{4}$. In our study, the prevalence of $\mathrm{CDH}$ was 26.3 per 10,000 live births. These two orthopaedic conditions have an excellent prognosis when diagnosed and treated early. In all our patients the treatment was initiated soon after birth reiterating the importance of screening all newborns with the simple Ortolani's and Barlow's tests with reference to congenital dislocation of hip.

Amaratunga and Chandrasekera (1989) have reported an incidence of 8.3 per 10,000 births for cleft lip with or without cleft palate and an incidence of 1.9 per 10,000 births for isolated cleft palate in central Sri Lanka ${ }^{5}$. A higher prevalence rate of 21.9 per 10,000 live births for cleft lip and cleft palate was observed in our study. It is important to note that the oro-maxillo-facial unit at Anuradhapura had facilities and expertise to initiate treatment early.

Prevalence of Down syndrome in Anuradhapura was 20.8 per 10,000 live births. In Britain it geographically varies between 18 (Glasgow) and 23.9 (Oxford) per 10,000 live births ${ }^{6}$. A statistically significant upward secular trend for Down syndrome has been noted in developed countries which could be partly explained by rising maternal age $^{2}$. The most consistent feature of Down syndrome is learning disability. Hence our findings indicate that at least 19 children with Down syndrome having special educational needs are annually added to the school going population from a single province of the island.
A preventable congenital anomaly which contributes significantly to perinatal and infant mortality is NTD. Lucas and Ediriweera (1996) have reported anencephaly as an important cause of infant mortality in a study conducted at a tertiary care maternity hospital in Colombo ${ }^{7}$. LBPR of neural tube defects in Anuradhapura was 13.2 per 10,000 live births, the affected babies having anencephaly, meningomyelocele or encephalocele. In Britain, the LBPR of neural tube defects varies between 11.9 (Oxford) and 17.2 (Glasgow) per 10,000 live births ${ }^{6}$. A decline in the prevalence of NTDs by between $31 \%$ and $78 \%$ has recently been observed in USA, Canada and Chile with the introduction of periconceptional daily supplements of synthetic folic acid ${ }^{8}$. Wickramasinghe et al have shown that only $6.6 \%$ of pregnant mothers attending a tertiary care maternity clinic in Colombo have taken preconceptional folic acid supplements 9 . Hence it is about time that we initiate a periconceptional folic acid supplementation programme targeting women of child bearing age to reduce neural tube defects and a few other congenital anomalies.

In addition to revealing baseline prevalence rates for selected congenital anomalies, our study also demonstrated the feasibility of maintaining a congenital anomaly register in a provincial hospital. We suggest that College of Paediatricians and Perinatal Society of Sri Lanka should explore the possibility of maintaining a national register of congenital anomalies, possibly in collaboration with the Epidemiology unit of the Ministry of Health. It is imperative to include cardiac anomalies and anomalies among stillbirths in such registers.

\section{References}

1. European Registration of Congenital Anomalies (EUROCAT) working group. Eurocat Report 7, Scientific Institute of Public Health-Louis Pasteur, Brussels, 1997. 
2. Dastgiri S, Stone DH, Le-Ha C, Gilmour WH. Prevalence and secular trend of congenital anomalies in Glasgow, UK. Archives of Disease in Childhood 2002; 86:257-63.

3. Roye DP, Roye BD. Idiopathic congenital talipes equinovarus. $J$ Am Acad Orthop Surg 2002; 10 (4):239-48.

4. Guille JT et al. Dysplasia of the Hip from Birth to Six Months. J Am Acad Orthop Surg $2000 ; 8$ (4), 232-42.

5. Amaratunga AN, Chandrasekera A. Incidence of cleft lip and palate in Sri Lanka. J Oral Maxillofac Surg 1989; 47(6):559-61.
6. Rankin J, Pattenden S, Abramsky L, Boyd P, Jordan H, Stone D, et al. Prevalence of congenital anomalies in five British regions, 1991-99 Arch Dis. Child Fetal Neonatal Ed 2005; 90(5): F374 - F379.

7. Lucas GN, Ediriweera RC. Perinatal deaths at the Castle Street Hospital for Women in 1993. Ceylon Med J 1996; 41(1):10-2.

8. Eichholzer M, Tonz O, Zimmermann R. Folic acid: a public-health challenge Lancet 2006; 367(9519):1352-61.

9. Wickremasinghe VP, Prageeth PP, Pulleperuma DS, Pushpakumara KS. Preconceptional care of women at booking visit at De Soysa Maternity Hospital and Castle Street Hospital for Women. Ceylon Med J 2003; 48(3):77-9. 